\title{
Paul d'Hollander (Dir.), Abbé Hippolyte Delor. Carnets (1837-1885)
}

Notes bibliographiques, index, illustrations, arbre généalogique, CDRom.

Limoges, Presses universitaires de Limoges, coll. " Matière à Histoire ", 2012, 286 p.

\section{Paul Airiau}

\section{(2) OpenEdition}

\section{Journals}

Édition électronique

URL : http://journals.openedition.org/assr/25513

DOI : $10.4000 /$ assr.25513

ISSN : $1777-5825$

Éditeur

Éditions de l'EHESS

\section{Édition imprimée}

Date de publication : 30 décembre 2013

Pagination : 217

ISSN : 0335-5985

\section{Référence électronique}

Paul Airiau, «Paul d'Hollander (Dir.), Abbé Hippolyte Delor. Carnets (1837-1885) », Archives de sciences sociales des religions [En ligne], 164 | 2013, mis en ligne le 04 mars 2014, consulté le 21 septembre 2020. URL : http://journals.openedition.org/assr/25513 ; DOI : https://doi.org/10.4000/assr.25513

Ce document a été généré automatiquement le 21 septembre 2020.

(C) Archives de sciences sociales des religions 


\section{Paul d'Hollander (Dir.), Abbé} Hippolyte Delor. Carnets

\section{(1837-1885)}

Notes bibliographiques, index, illustrations, arbre généalogique, CDRom.

Limoges, Presses universitaires de Limoges, coll. « Matière à Histoire ", 2012, 286 p.

Paul Airiau

\section{RÉFÉRENCE}

Paul d'Hollander (Dir.), Abbé Hippolyte Delor. Carnets (1837-1885), Notes bibliographiques, index, illustrations, arbre généalogique, CD-Rom, Limoges, Presses universitaires de Limoges, coll. « Matière à Histoire », 2012, 286 p. 
1 Si l'on ne trouve pas toujours tout dans les archives, si l'on n'y trouve parfois rien, on $\mathrm{y}$ découvre aussi régulièrement des documents inattendus, arrivés là on ne sait comment, mais pour le moins à la plus grande satisfaction des historiens. C'est le cas avec les pièces 4935 à 4950 de la Bibliothèque universitaire de Limoges. Ces 3200 pages manuscrites représentent les carnets des mémoires-coutumier-journal de l'abbé Hippolyte Delor, passés on ne sait comment, des mains de ses héritiers à la bibliothèque du grand séminaire de Limoges puis à celle de l'université.

2 Né en 1810, mort nonagénaire et alors honoré d'une nécrologie par L'Univers, l'abbé Hippolyte Delor eut un parcours sacerdotal d'une simplicité redoutable: issu d'une famille commerçante peu religieuse, petit séminariste de 1824 à 1827, diacre en 1832 et professeur de

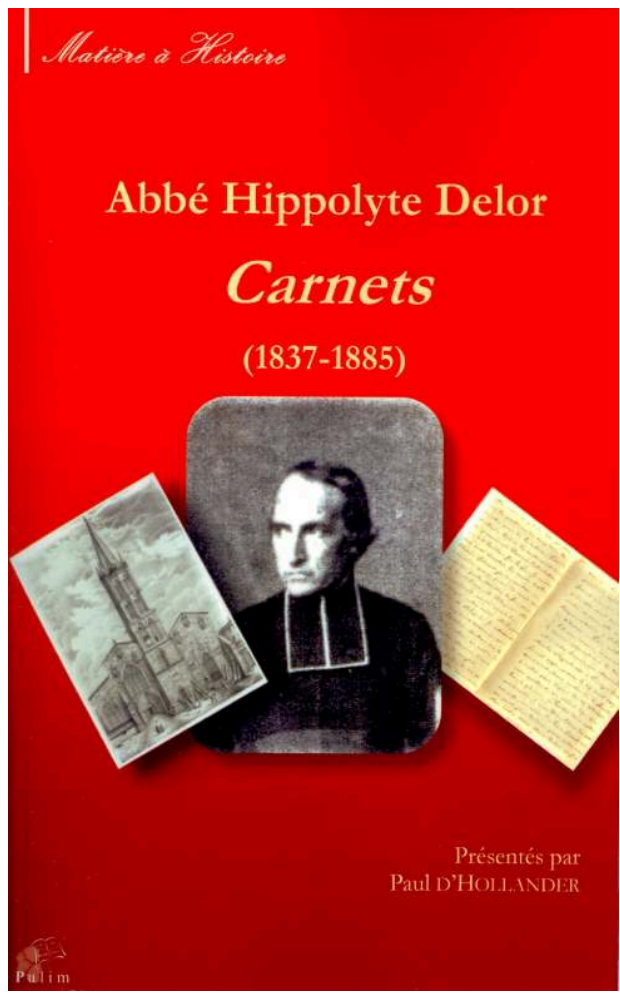
rhétorique au collège diocésain de Felletin, prêtre en 1833, en 1844 déchargé du professorat au profit des catéchismes et conférences, activité conjuguée avec celle de prédicateur, en 1847 curé de Saint-Pierre de Limoges, la plus grosse paroisse de la ville. Ajoutons un canonicat, des responsabilités diocésaines, et le tout est dit.

3 À partir de 1837, il commence à prendre des notes plus ou moins espacées, qui finiront donc par former un ensemble conséquent dont certains éléments ont été malheureusement perdus (octobre 1847-mars 1854, février 1859-mars 1863, novembre 1870-mars 1873). Ce sont ces carnets que Paul d'Hollander retranscrit et éclaire. Ayant présenté le curé et sa production littéraire intime, dont il précise le statut et les modalités matérielles de la réalisation, il en propose ensuite une série de longs extraits, organisés en plusieurs thèmes : l'homme, la famille, le collège de Felletin, le curé de Saint Pierre, le prêtre, la prédication, les pèlerinages, les admirations (Montalembert, Veuillot, l'évêque de Tulle et ancien limougeaud Mgr Berteaud), la vie locale. Un CDRom joint à l'ouvrage permet d'accéder à l'intégralité des carnets transcrits (format pdf), une table des matières de chaque carnet permet d'y effectuer un premier repérage.

Des éléments que souligne Paul d'Hollander, on en retiendra un : l'appartenance de l'abbé Delor à un catholicisme d'affirmation, qui, entre le versant libéral et le versant intransigeant, choisit le dernier et se romanise avec lui. Cependant, l'intransigeance n'est point chez lui polémique. Il est radicalement longanime, d'où peut-être son affection indéfectible pour Montalembert, son calme lors de la promulgation du Syllabus, son souci de ne pas mettre ses confrères prêtres en porte à faux lorsqu'il est question de manifester en corps l'appui au projet de proclamation de l'infaillibilité pontificale comme dogme, sa correspondance avec George Sand et une lettre de consolation à Paul Bert après la mort de Gambetta. Alors qu'on est plus habitué à 
rencontrer des intransigeants de combat, polémistes en diable et batailleurs au possible, la chose mérite d'être relevée. Est-ce une irréductible individualité qui joue, son milieu familial, sa formation sacerdotale, ses choix spirituels (il admire Mgr Charles Gay, dont la spiritualité s'accompagne sans difficulté de la proximité avec le cardinal Pie) ? Il est difficile de répondre, mais creuser ce cas particulier pourrait donner de mieux approcher l'articulation entre l'individualité et l'habitué, ou, pour le dire autrement, la manière dont les particularités de caractère et de tempérament s'expriment malgré, ou par, ou à travers, les habitus.

Indéniablement, l'auteur donne là une utile édition de source, dont on aimerait qu'elles se multiplient. Car elle offre un dépaysement plus important que ce que l'on pourrait penser, tant ce curé du $\mathrm{XIX}^{\mathrm{e}}$ siècle est en fait bien éloigné de notre $\mathrm{XxI}^{\mathrm{e}}$ siècle commençant, le sentiment d'exotisme se nourrissant de l'indéniable proximité. En effet, la vie quotidienne d'un prêtre d'autrefois, de temps révolus, surgit ici avec son étrangeté. Les horaires sont calqués sur ceux du soleil et articulés aux impératifs pastoraux. On ne compte plus les levers à trois, quatre, cinq heures du matin, les premières messes à cinq heures trente et ainsi de suite (p. 45-46, 48, 80). Les voyages durent longtemps, très longtemps, en première, seconde ou troisième classe, avec des changements au milieu de la nuit, des wagons et des compartiments sans communication entre eux (p. 46-48, 172-173, 177). Les confessions, pascales notamment, s'étalent sur des journées entières, sans interruption ou presque, au chœur de l'église pour les hommes (un enjeu! mais traité en quelques six minutes, c'est-à-dire la durée accordée à chacun des pénitents - un enjeu, tout comme la mort chrétienne de ces mêmes hommes, p. 120-129) et au confessionnal pour les femmes (expédiées plus vite semble-t-il, p. 92-94). La prédication (p. 155-168) est fondamentale, dans sa durée, son contenu, ses modalités : point trop longue (au-delà d'une heure, c'est beaucoup), usant correctement des méthodes rhétoriques, s'appuyant sur des techniques corporelles opportunes (voix posée, jeu sur le volume et les émotions, la rapidité du débit...).

Ajoutons-y, en ce qui concerne l'identité masculine, la présence de l'émotion, par le biais des amitiés (p. 37), des larmes (p. 37, 39, 65-66, 78-79, 207, 209), de la poésie (p.180) et des impressions religieuses (p.57, 136, 169, 187), notamment lors des pèlerinages. En ce qui a rapport avec l'identité sacerdotale (notamment p. 91-94), relevons la performance physique que peut représenter le travail pastoral (écouter des confessions, prêcher, organiser des cérémonies, célébrer le culte - messes et offices), les contraintes canoniques (obtenir les pouvoirs dans les diocèses que l'on traverse pour pouvoir y exercer son ministère), la relative facilité à dire la messe dans les multiples institutions religieuses parsemant le territoire (p.46,176), et la sociabilité sacerdotale (p. 200-211), notamment en se servant réciproquement la messe (p. 175 - il n'y a pas de concélébration). L'ensemble donne l'image d'une véritable livraison des prêtres à leur fonction, d'une profonde incorporation et «impsychation » de l'identité sacerdotale, sans que paraisse de distance entre l'acteur et le rôle - sans que, justement, l'acteur semble se penser et se vivre comme acteur et non comme agissant, ce qu'il est. Bref, les carnets d'Hippolyte Delor sont une source à travailler, et à travailler en profondeur. Grâces soient donc rendues à Paul d'Hollander et aux institutions qui les rendent disponibles. 